\title{
Preclinical study to evaluate the effects of a soft handkerchief in nasolabial skin barrier
}

Samara Eberlin ${ }^{1}$, Liliana Torloni ${ }^{2}$, Angélica Richart Csipak ${ }^{2}$, Gustavo Facchini ${ }^{1}$, Gustavo Henrique da Silva ${ }^{1}$, Camila Martins Kawakami ${ }^{1}$ PhD, Ana Lúcia Tabarini Alves Pinheiro' ${ }^{1}$, Vivienne Carduz Castilho ${ }^{2}$

${ }^{1}$ Kosmoscience Group, Campinas/SP - Brazil.

${ }^{2}$ Libbs Farmacêutica Ltda, São Paulo/SP-Brazil.

*Corresponding Author: Samara Eberlin, Kosmoscience Group, Rua Sandoval Meirelles, 72 - Vila João Jorge, CEP: 13040-315 -

Campinas/SP, Brasil.

Received date: June 03, 2021; Accepted date: July 08, 2021; Published date: July 16, 2021

Citation: S Eberlin, L Torloni, A RCsipak, G Facchini, G H da Silvat et al. (2021) Preclinical study to evaluate the effects of a soft handkerchief in nasolabial skin barrier. J. Dermatology and Dermatitis. 6(2); Doi:10.31579/2578-8949/078

Copyright: (2021 Samara Eberlin, This is an open-access article distributed under the terms of The Creative Commons. Attribution License, which permits unrestricted use, distribution, and reproduction in any medium, provided the original author and source are credited.

\begin{abstract}
People suffering from an ordinary acute cold consume so many handkerchiefs that the wiping actions on their own increase the abrasive damage of the nasolabial zone, finally leading to a disturbed barrier function and inflamation. It seems that the quality of the material used for nose cleansing could play an important role and that innovative handkerchiefs would fulfil a preventive role in minimizing the damaging effect of the skin barrier function of the nasolabial zone during this conditions. The objective of this work was to evaluate the effects of a wet handkerchief (SKNW) on the skin barrier balance by measuring filaggrin and histamine using an experimental model of ex vivo native human skin model and the interference of this handkerchief in the skin microbiota through in vitro screening. SKNW showed an increase in the production of filaggrin and a reduction of histamine synthesis in human explants subjected to barrier disruption with 5\% Sodium Lauryl Sulfate. Additionaly, SKNW showed a mild and moderate antiseptic action on the evaluated microorganisms. This study demonstrated that SKNW could be considered a feasible option for consecutive wiping of nasolabial zone avoiding the transient mechanical dermatitis, considering its skin barrier protective, non-irritating and antiseptic actions.
\end{abstract}

Key words: skin barrier; fillagrin, histamina; sensitive skin; wipes; skin care; ex vivo; skin; microbiota

\section{Abbreviations}

$\mathrm{SC}-$ Stratum corneum

SKNW - Salsep $®$ Kids Nasal Wipes

IL-1 $\alpha$ - interleukin-1 alpha

IL-1 $\beta$ - interleukin- 1 beta

TNF $\alpha$-Tumor necrosis fator $\alpha$

NMFs - Natural moiusturizing factors

BHI - Brain Heart Infusion Broth

$\mathrm{CFU}-$ Colony forming units

\section{Introduction}

The occurrence of runny nose due to rhinitis, flu and colds is very common in infants. Published studies carried out in Brazilian children have shown that about $48 \%$ had at least one episode of sneezing, runny nose or stuffy nose without a cold or flu in the first year of life, and that the average prevalence of rhinitis in children was $26.6 \%[1,2]$.
Under this clinical situation, frequent rubbing of the nasolabial skin with handkerchiefs can provoke skin irritation, which - at first - heals difficultly because the skin reacts by an inflammatory response leading to hyperkeratotic scaly areas. These clinical symptoms of a mechanically induced dermatitis probably are caused by removal of the superficial hydrolipidic layer and disturbance of the barrier function in the upper part of the Stratum corneum (SC) [3].

The natural barrier of SC depends on its composition, formed mostly by highly insoluble and resistant proteins, which involve externally keratinocytes being fundamental in the structure and organization of intracellular lipids [4]. Profilaggrin, filaggrin, involucrin and loricin are examples of these proteins which are responsible for the association of intermediate keratin filaments and consequent increase of cohesion among corneocytes [4].

Insult of skin barrier promotes immediately release of pro-inflammatory cytokines, along chemokines and growth factors, which will stimulate the migration andproliferation of immunocompetent cells [5]. Inflammatory signaling via nuclear transcription factor kappa B (NF-Kappa B) is also activated and results in the production of more cytokines and chemokines, as well as, trigger the classic pathway of inflammation and increasing the 
production of eicosanoids, such as prostaglandins and leukotrienes [6,7]. Furthermore, a variety of mediators, such as, vascular endothelial growth factor, nitric oxide and histamine are produced leading to vasodilation, edema, mast cell degranulation, pain and itching, exacerbating the inflammatory process and skin sensivity [6, 8-9].

Concurrently, local microbiota can be significantly disturbed resulting in a cutaneous dysbiosis that unbalances the immune system and favors the growth of pathogenic microorganisms, predisposing to secondary infections [10-12].

It seems that the quality of the paper material used for nose cleansing could play an important role and that soft handkerchiefs would cause less damage on the hydrolipidic film and the skin barrier when having a cold. Soft paper handkerchiefs might then fulfil a preventive role in minimizing the damaging effect of the skin barrier function of the nasolabial zone [13].

The objective of this work was to evaluate the effects of a skin care handkerchiefs on the nasolabial skin barrier balance by measuring filaggrin and histamine using an experimental model of ex vivo native skin. Additionally, an in vitro screening was carried out with the purpose of evaluating the interference of these wipes in skin microbiota.

\section{Material and Methods}

\section{Test substance}

Test substance consists of a wet handkerchief - Salsep ${ }^{\mathrm{R}}$ Kids Nasal Wipes (SKNW) mainly indicated for cleaning nasal secretions, crusts and runny nose caused by flu,colds and rhinitis in infants. SKNW was provided by Libbs Farmacêutica Ltda, São Paulo/SP - Brazil (INCI names: Aqua, Myristamidopropyl PG-Dimonium Chloride Phosphate, Sodium Chloride, Tocopheryl Acetate, Aloe Barbadensis leaf juice, Glycerin, Chamomilla Recutita Flower Extract, Potassium sorbate, Decyl Glucoside, Citric acid, Sodium citrate, Sodium benzoate).

\section{Skin fragments culture}

Human skin fragments were originating from one (01) healthy donor, female, skin type III, 43 years, who underwent elective plastic surgery in the abdominal region (abdominoplasty). After the surgical procedure, the skin fragments were collected in plastic vials containing $0.9 \%$ saline and kept in refrigeration for up to 24 hours. The use of human skin fragments from elective surgeries for this study was approved by the Ethics Committee of the University São Francisco - SP.

\section{Treatment protocols and stress conditions for skin culture}

Skin fragments were fractionated into pieces of approximately $1.5 \mathrm{~cm}^{2}$ and incubated in culture medium (DMEM; Sigma-Aldrich, San Luis, MO, USA) in air-liquid interface at $37^{\circ} \mathrm{C}$ in a humidified atmosphere with $5 \%$ $\mathrm{CO}_{2}$. Fragments were treated with SKNW, simulating the condition of using a wet wipe for 3 consecutive days. On the third day, the fragments were subjected to barrier disruption with Sodium Lauryl Sulfate (5\% SLS; Sigma) and treated with SKNW. After 24 hours the third treatment, the skin culture supernatant was collected for measurement of histamine and the fragments subjected to histological processing for immunofluorescence and semi-quantification of filaggrin.

\section{Quantification of histamine}

Concentrations of histamine were measured by ELISA using commercially available kit (Uscn Life Sciences, Wuhan, China). Absorbance reading was performed on Multiskan GO monochromator (Thermo Fisher Scientific, Waltham, MA, USA).

\section{Immunofluorescence evaluation for Filaggrin}

Skin fragments were fixed in 4\% paraformaldehyde ( $\mathrm{pH} 7.4$ ) for 24 hours and cryoprotected in a $30 \%$ sucrose solution for 72 hours. Fragments were embedded in a formulation of water-soluble glycols and resins (TissueTek ${ }^{\circledR}$ OCT TM, Torrance, CA, USA) and then $10 \mu \mathrm{m}$ serial sections were collected directly on silanized slides with the aid of cryostat (Leica CRYOCUT 1800, Germany). Slides were incubated overnight with primary antibody anti-FILAGGRIN (Abcam, Cambridge, UK). Subsequently, the cuts were washed and incubated with Alexa Fluor 488 secondary antibody - Goat anti Rabbit (Thermo Fisher Scientific). DAPI (4'-6-Diamidino-2-Phenylindol; DNA marker; Sigma-Aldrich) was used as a DNA marker. The slides were mounted in a specific mounting medium and analyzed using a Fluorescence Microscope (OLYMPUS) with the aid of the cellSens Standard software (C) 2010 OLYMPUS CORPORATION, Center Valley, PA, USA). The evaluated parameter was the fluorescence intensityemitted by the specific antibody labeling. After obtaining the images, the fluorescence intensity was quantified with the aid of the ImageJ software (Arbitrary Units - A.U.)

\section{Statistical analysis}

For statistical evaluation, ANOVA test was used to measure the variation of the results, comparing the data between all the groups. We applied the Bonferroni post-test, which strengthened and made the result presented in the ANOVA more precise (GraphPad Prism6, Version 6.01, GraphPad Software, Inc., La Jolla, CA, USA). A 5\% significance level was used.

\section{Microbiological inhibition}

The antibacterial activity of SKNW was assessed through agar diffusion test against three bacteria species: Staphylococcus aureus ATCC 6538 (American Type Culture Collection, Rockville, MD), Staphylococcus epidermidis ATCC 12228 and Cutibacterium acnes ATCC 6919. The microorganisms were maintained in $\mathrm{BHI}$ for $24 \mathrm{~h}$ at $35^{\circ} \mathrm{C}$ and each bacterial suspension (inoculum) was diluted to $10^{8} \mathrm{CFU} / \mathrm{mL}$ and uniformly spread on a sterile Petri dish containing Muller Hinton agar. SKNW was cut into $1 \mathrm{~cm}^{2}$ and added to each of the 3 wells $(8 \mathrm{~mm}$ diameter holes cut in the agar gel, $20 \mathrm{~mm}$ apart from one another). The systems were incubated for $48 \mathrm{~h}$ and the inhibition of the bacterial growth around each well was measured in $\mathrm{mm}$. The inhibition was classified as mild halo up to $4 \mathrm{~mm}$, moderate - halo from $5 \mathrm{~mm}$ to $9 \mathrm{~mm}$, and strong halo above $10 \mathrm{~mm} \mathrm{[14].}$

\section{Results and Discussion}

In this work, we present a combination of preclinical results obtained for a wet handkerchief (SKNW) mainly indicated for cleaning nasal secretions, crusts and runny nose caused by flu, colds and rhinitis, considering the skin barrier protective, non- irritating and antiseptic actions. These characteristics are desired for this category of products, considering the need for repeated use for hygiene of the nasal region in situations of runny nose. The softness of material used for cleaning nasolabial area is determining to cause less damage on skin barrier during flu crisis [13].

A wide variety of methods can be employed to measure the in vitro activity of microorganisms against antimicrobial agents in products, which can be classified into three types: bioautographic, diffusion and dilution assays [15]. To evaluate the antiseptic action of the SKNW, we opted by agar diffusion method. Diffusion antibiogram testing is a conventional way to measure antimicrobial activity and is based on diffusion of the product or substance into a solid culture medium with the inoculated microorganism. From this diffusion, a halo appears around the product if it has antimicrobial properties [15-16]. The reading of the results is done after 48 hours, whereit is checked the presence or absence of halo formation around the orifice where the sample is placed.

SKNW promoted a mild to moderate inhibition in the growth of Staphylococcus aureus, Staphylococcus epidermidis and Cutibacterium 
acnes, as described in Table 1. Specifically, the inhibition zone was 1.90 $\mathrm{mm}$ for Staphylococcus aureus (mild inhibition), $6.42 \mathrm{~mm}$ for Staphylococcus epidermidis (moderate inhibition) and $5.58 \mathrm{~mm}$ (moderate inhibition) for Cutibacterium acnes. Regarding the experimental controls, there was proper development of the microorganisms evaluated in the positive control plates and in the negative control there was no type of growth (Figure 1).

Bacteria evaluated in this study are part of the skin microbiota and play an important role in the maintenance of cutaneous metabolism. The balance between the populations of Staphylococcus aureus, Staphylococcus epidermidis and Cutibacterium acnes, can attribute beneficial properties to products applied topically, particularly in certain skin conditions, such as transient barrier disturbance, sensitive skin, dermatitis, and acne [17-18]. Clearly, this is only a preliminar result, however despite the limitations of the present study, we can suggest that SKNW showed a mild and moderate antiseptic action on the evaluated microorganisms.

\begin{tabular}{|l|c|l|}
\hline Microorganisms & $\begin{array}{c}\text { Inhibition halo } \\
(\mathbf{m m})\end{array}$ & Classification \\
\hline Staphylococcus aureus (ATCC 6538) & $1.90 \pm 0.58$ & Mild inhibition \\
\hline Staphylococcus epidermidis (ATCC 12228) & $6.42 \pm 1.02$ & $\begin{array}{l}\text { Moderate } \\
\text { inhibition }\end{array}$ \\
\hline Cutibacterium acnes (ATCC 6919) & $5.58 \pm 0.52$ & $\begin{array}{l}\text { Moderate } \\
\text { inhibition }\end{array}$ \\
\hline
\end{tabular}

Table 1. Results and classification of inhibition halos obtained for each microorganism evaluated.

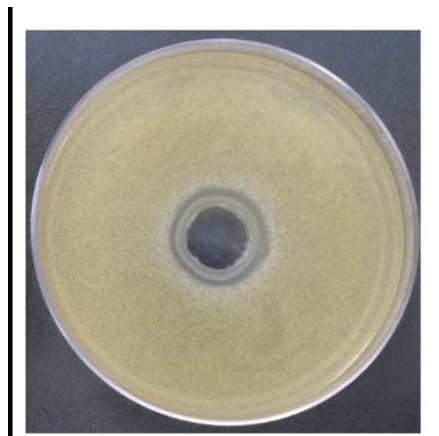

Staphylococcus aureus

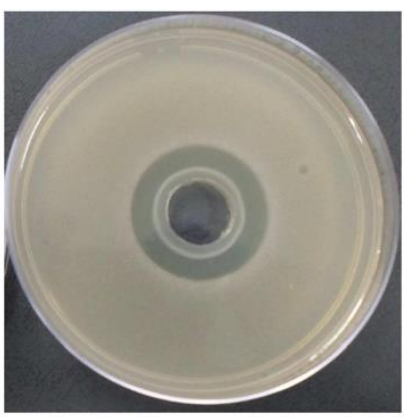

Staphylococcus epidermidis

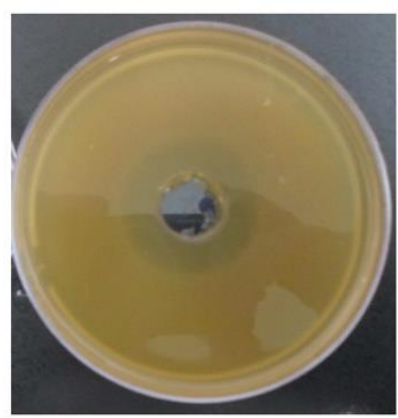

Cutibacterium acnes

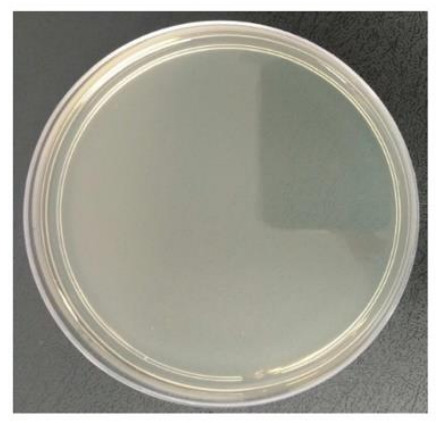

Positive control

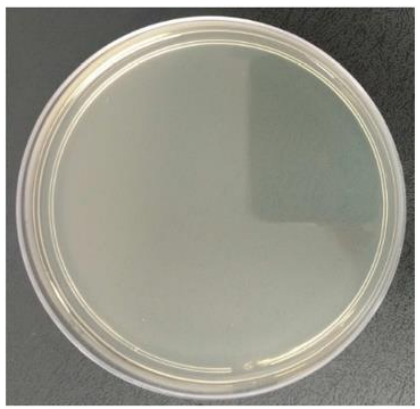

Positive control

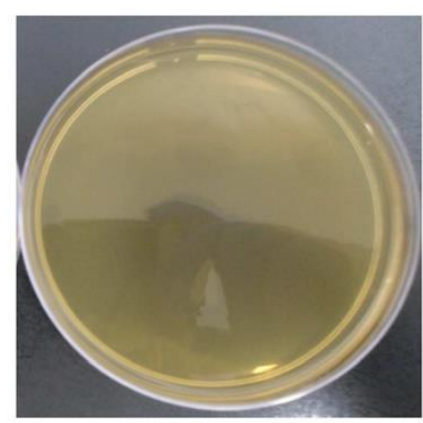

Positive control

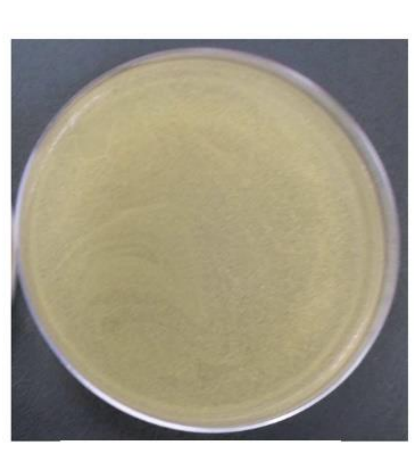

Negative control

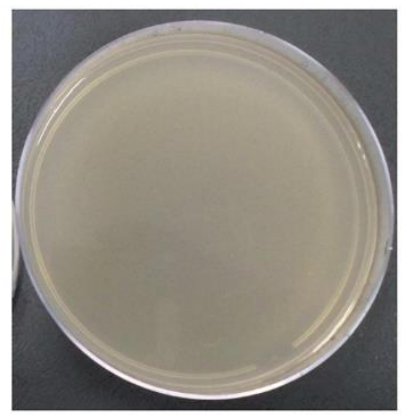

Negative control

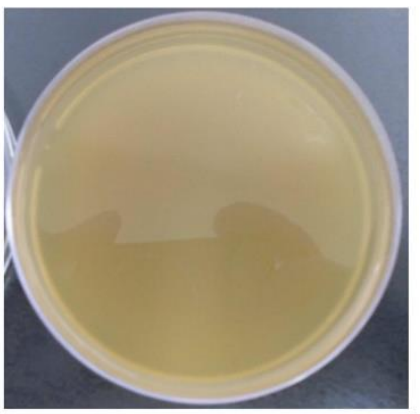

Negative control 
Figure 1. Inhibition halo formed after incubation of the microorganisms Staphylococcus aureus, Staphylococcus epidermidis and Cutibacterium acnes with SKNW and their respective control groups

Regarding the protective ability on skin barrier, we evaluated in this work the effects of SKNW on the production of envelope protein filaggrin using ex vivo human skin model submitted to epidermal barrier disruption [1921]. Figures 2 and 3 represent the results of immunostaining and and subjected to barrier disruption with Sodium Lauryl Sulfate (5\% - SLS). As expected protein semi-quantification of filaggrin, respectively, in human skin culture treated with SKNW, barrier disruption induced with $5 \%$ SLS produced a $59.32 \%$ reduction in filaggrin synthesis when compared to baseline control $(\mathrm{P}<0.001)$. On the other hand, skin fragments subjected to irritative stress with SLS and treated with SKNW showed an increase of $103.39 \%$ in the production of filaggrin, when compared to the group only stressed with LSS $(\mathrm{P}<0.01)$.

These results allow us to infer that SKNW has a positive effect on the protection and maintenance of skin barrier by increasing the synthesis of filaggrin. The epidermal protein profilaggrin, lately synthesized during epidermal differentiation, plays a importante role in generating and maintaining SC flexibility and moisturizing [22]. This highly phosphorylated protein is quickly dephosphorylated and proteolyzed during the end of the transition from granular keratinocyte to the corneocyte, where it remains retained. During the transition from the granular layer to SC, profilaggrin is converted tofilaggrin by proteolysis and dephosphorylation [23-26]. In the SC, filaggrin is released from the interactions with keratin [27] and completly degraded into amino-acid constituents, which in turn, constitute approximately $50 \%$ of natural moiusturizingfactors (NMFs). NMFs are crucial for the maintenance of the epidermal moisture barrier, and they are reduced in dry skin, particularly during aging and seasonal alterations [27].
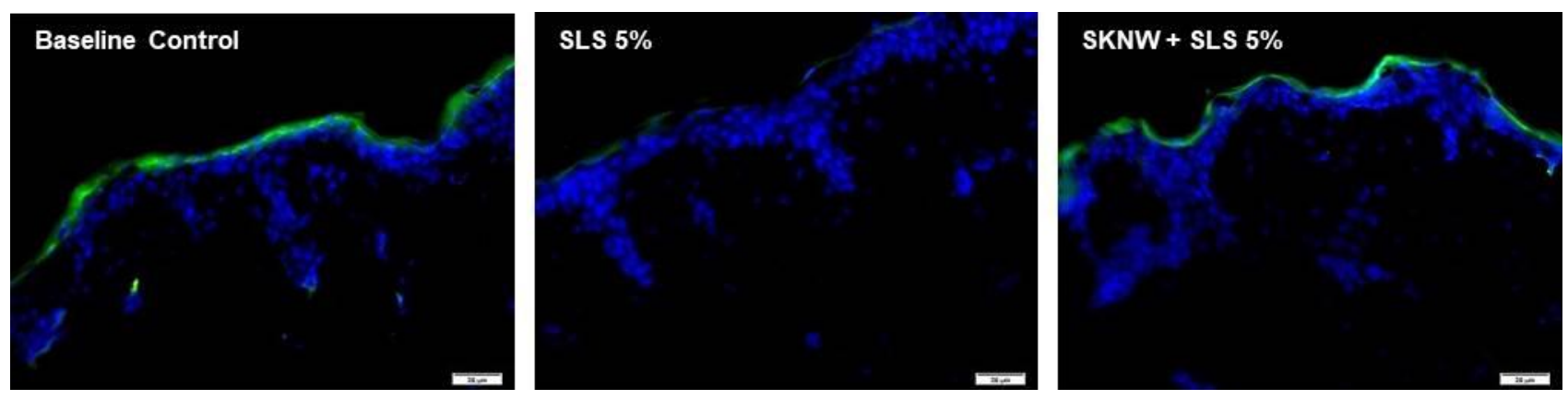

Figure 2: Immunofluorescence evaluation of filaggrin protein labeling in human skin fragments incubated with the evaluated product SKNW and submitted to barrier disruption with Sodium Lauryl Sulfate $(5 \%$ - SLS). Filaggrin is marked in green and the blue mark represents the cell nucleus (DNA).The reference bar corresponds to $20 \mu \mathrm{m}$.

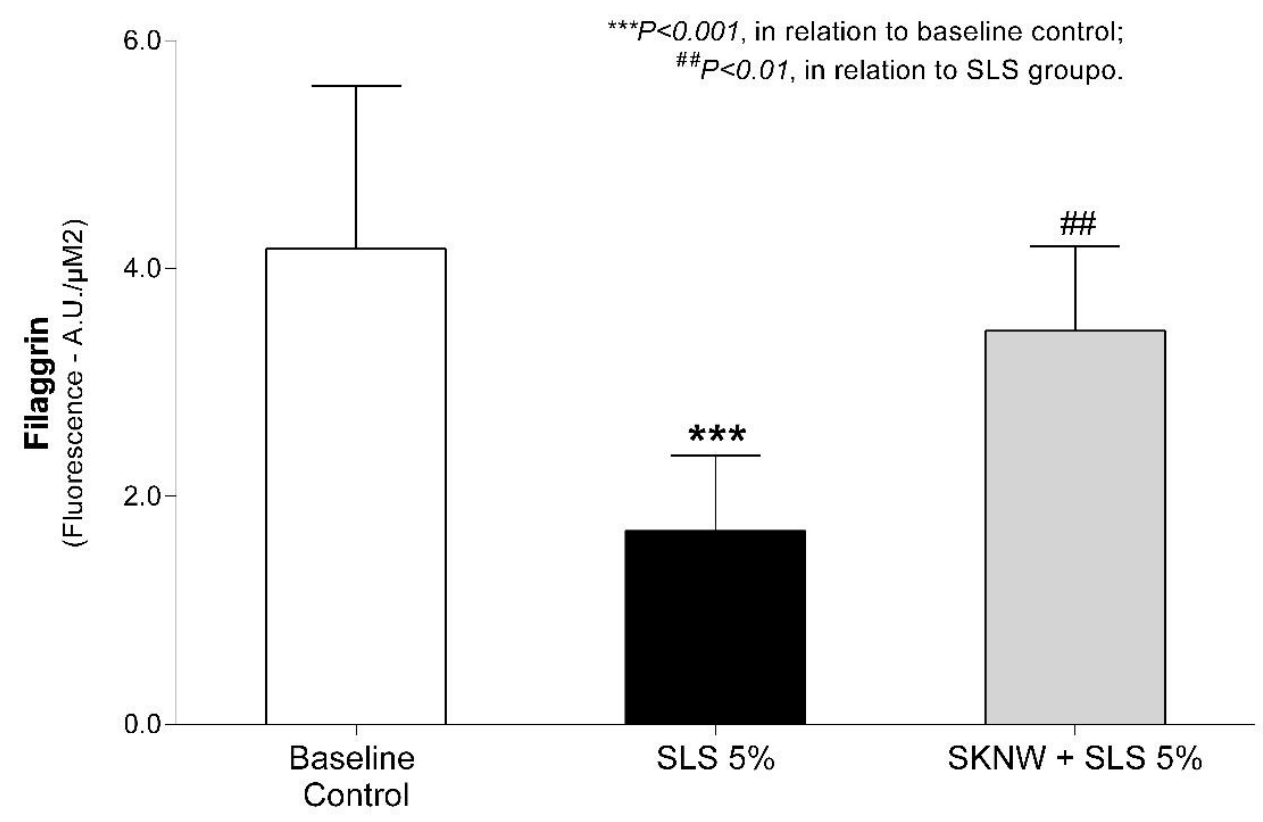

Figure 3: Semi-qualification of the fluorescence intensity of filagrin protein immunostaining in fragments of human skin fragments incubated with the evaluated product SKNW and submitted to barrier disruption with Sodium Lauryl Sulfate (5\% - SLS). The data represent the mean +- standard deviation of 09 areas (ANOVA - Bonferroni). 
Another important aspect to be considered during mechanically induced skin irritation is the exacerbation of the inflammatory response that occurs due to the increased permeability of the skin barrier [28-30]. Several inflammatory mediators are locally produced stimulating skin mast cells activation and histamine release, which in turn, result in degranulation, growth and/or survival of skin mast cells through the high affinity to the neurokinin-1 (NK-1) receptor [31-33]. Histamine is one of the most important mediators released during the first stage of allergic and irritating reaction [31] and is involved with pruritus, erythema and scaliness [34]. In the skin, beyond the mast cells, keratinocytes also produce and release histamine in response to stimuli [35-36]. Histamine exerts its effects by binding to its receptors (H1R to H4R), present in keratinocytes (H1R, H2R and H4R) and Langerhans cells (H4R) [37], which activatethe inflammatory signaling pathway NF Kappa B [38].

In this study, we evaluated the effects of the SKNW on the production of histamine in human skin cultures subjected to barrier disruption with $5 \%$ SLS and the results are shown in Figure 4. As can be seen, the barrier disruption with SLS increased histamine production by 52.26 times compared to baseline control $(P<0.001)$. The treatment with SKNW was able to significantly reduce the excessive production of this mediator by $60.02 \%(P<0.01)$, when compared to the SLS group.

This result points to an antihistaminic action of the SKNW, which indirectly acts through anti-inflammatory mechanisms, such as inhibition of mast cell and basophildegranulation, inhibition of adhesion molecules and cell chemotaxis, enhancingapoptosis of inflammatory cells and reduction of cytokine/chemokine expression [39].In addition to the effects on the inhibition of inflammatory and irritative response, the downregulation of histamine production promotes the recovery of skinbarrier. Studies indicate that the excessive production of histamine suppressedepidermal differentiation by significant reductions in filaggrin, loricrin and keratin 10expression in keratinocytes cultures and epidermal human models, mediated by H1Ractivation on keratinocytes [40]. Besides, it has been known that histamine disruptstight junctions, reduces transepithelial electric resistance (TEER) and enhances permeability in human skin explants [33].

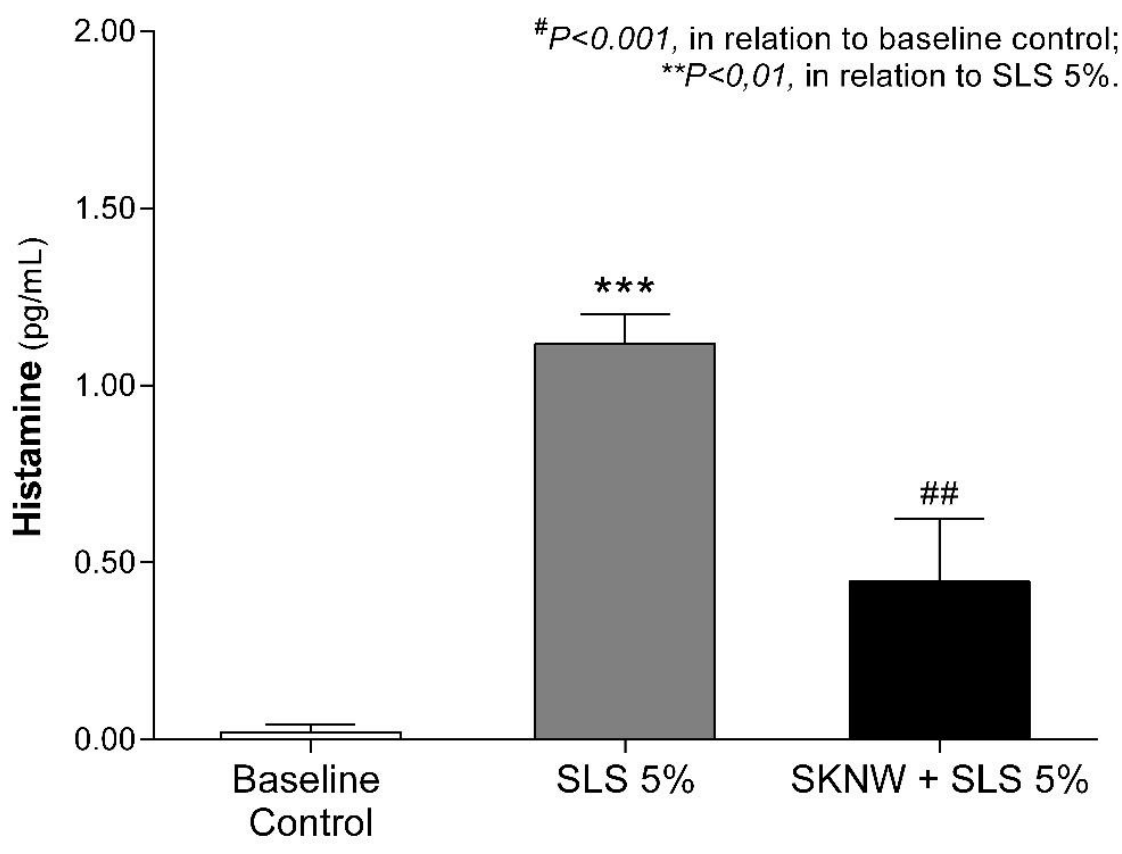

Figure 4: Effects of evaluated product SKNW on histamine production in human skin fragments submitted to barrier disruption with Sodium Lauryl Sulfate $(5 \%$ - SLS). The data represent the mean \pm standard deviation of 03 replicates (ANOVA - Bonferroni).

The promising effects promoted by SKNW in this work can be attributed to its composition - Tocopheryl Acetate, Aloe barbadensis (leaf juice) and Chamomilla recutita (flower extract).

Tocopheryl acetate, also known as vitamin E acetate, is a synthetic form of vitamin $\mathrm{E}$ which is widely used in dermatological products mainly for its undeniable antioxidant action [41]. Vitamin $\mathrm{E}$ is part of the antioxidant defense system of the organism and has important photoprotective and anti-photoaging role in the skin [42]. In the epidermis, tocopheryl acetate inhibits the production of prostaglandin E2, nitric oxide and protects against lipid peroxidation and edema formation induced by UV radiation [43-45]. In patients with atopic dermatitis, daily supplementation of 400 IE of vitamin $\mathrm{E}$ promoted a reduction in $\operatorname{IgE}$ levels and the clinical manifestations of this disorder [45]. In vitro and clinical studies also indicate an anti-inflammatory action of alpha tocopherol through inhibition of $\mathrm{NF} \square \mathrm{B}$ and proinflammatory cytokines [47-49].

Aloe barbadensis Miller or Aloe vera Linne is a tropical succulent plant widely used from skin disorders. It can be effective for psoriasis, seborrheic dermatitis, aphthous stomatitis, xerosis, lichen planus, frostbite, genital herpes, human papilloma virus, burn, wound healing and inflammation [50-55]. It can also be used for its antimicrobial and antifungal properties, in addition to photodynamic therapy of some cancers [50]. Maenthaisong et al. conducted a meta-analysis clinical study that showed the healing time for burn wound, for first to second degree, in Aloe vera treated-group was 8.79 days shorter than those in the control group [51]. Regarding skin effects, Aloe vera was described to stimulate collagen and hyaluronic acid production by human dermal fibroblastos [54]. Oral intake of Aloe vera contibutes to maintaining healthy skin, since skin elasticity, collagen score, skin moisturizing and transepidermal water loss were significantly improved after 12-week of use [54]. Likewise, hydration and skin barrier improvement of Aloe extract were confirmed after 2-weeks of topicalapplication [56].

The mechanisms by which this plant exerts its effects are closely linked 
to its diverse composition of polysaccharides, glycoproteins, lectins, anthraquinones and phenolic compounds, among others. Mucopolysaccharides exert protective effects on epitelial barriers, such as, stomachs and duodenum, reducing the susceptibility to allergies and irritations [52]. Aloe also presents antioxidants, anti-inflammatory and a strong immunomodulatory properties, activating macrophages which gives an antimicrobial action to this species [53].

Another ingredient presents in SKNW is the Chamomilla recutita flower extract,defined by Srivastava et al. as "a herbal medicine of the past with bright future" [57]. In fact, chamomile is one of the oldest, most widely used and well documented medicinal plants in the world and has been recommended for a variety of healing applications [58]. Terpenoids and flavonoids are the main bioactive constituents of chamomile and present anti-inflammatory and antioxidants activities [59-60]. Chamomile is vastly used to treat inflammations of the skin and mucous membranes, such as diaper rash and cracked nipples, and for various bacterial infections of the skin, oral cavity and gums, and respiratory tract [61-62]. A clinical study demonstrated that chamomile flavonoids and essential oils penetrate skin surface into the deeper skin layers [63]. This fact supports their use as topical antiphlogistic (anti-inflammatory) agent through mechanisms that involve inhibition of LPS-induced prostaglandin E2 release and attenuation of cyclooxygenase (COX-2) enzyme activity without affecting the constitutive form, COX-1 [65]. In this respect, topical applications of chamomile have been shown to be moderately effective in the treatment of atopic eczema [65]. It was found to be about $60 \%$ as effective as $0.25 \%$ hydrocortisone cream [66]. Compared to corticosteroids, chamomile was also suggest to present faster and complete woundhealing [67].

In summary, this preclinical study showed that the combination of specificingredients in SKNW was able to present a considerable approach in the mechanisms involving in skin barrier integrity. This study demonstrated that SKNW could be considered a feasible option for consecutive wiping of nasolabial zone avoiding the transient mechanical dermatitis, considering its skin barrier protective, non-irritatingand antiseptic actions.

Acknowledgements: This work was supported by grants from Libbs Farmacêutica Ltda. The authors also express many thanks to Dr. Mark Little for their technical assistance.

\section{References}

1. Chong Neto HJ, Bojarski LFM, Rosário CS, Rosário BA, Chong FH, Grasselli EA, et al (2014). Allergic rhinitis in preschool children from southern Brazil. Allergy 69: 545-547.

2. Solé D, Camelo-Nunes IC, Vana AT, Yamada E, Werneck F, Freitas LS, et al (2004). Prevalence of rhinitis and relatedsymptoms in schoolchildren from different cities in Brazil. Allergol et Immunopathol 32(1):7-12.

3. Houben E, Adam R, Hachem JP, Roseeuw D, Rogiers V, Paepe K (2008). Clinical scoring and biophysical evaluation of nasolabial skin barrier damage caused by rhinorrhea. Contact Dermatitis 59: 296-300.

4. Ishida-Yamamoto A, Iizuka H (1998). Structural organization of cornified cell envelopes and alterations in inherited skin disorders. Exp Dermatol 7: 1-10.

5. Williams IR, Kupper TS (1996). Immunity at the surface: homeostatic mechanisms of the skin immune system. Life Sci 58: 1485-1507.

6. Paus R, Theoharides TC, Arck PC (2006). Neuroimmunoendocrine circuitry of the ,brain-skin connection ${ }^{\text {ee }}$ Trends Immunol 27: 32-39.

7. Luger TA (2002). Neuromediators - a crucial component of the skin immune system. J. Dermatol Sci 30: 87-93.
8. Grouzmann E, Bigliardi P, Appenzeller M, Pannatier A, Buclin $T$ (2011). Substance P-induced skin inflammation is not modulated by a single dose of sitagliptin in human volunteers. Biol Chem 392: 217- 221.

9. Misery L, Myon E, Martin N, Consoli S, Bousetta S, Nocera T, et al (2007). Sensitive skin: psychological effects and seasonal changes. J Eur Acad Dermatol Venereol 21: 620-628.

10. Baldwin HE, Bhatia ND, Friedman A, Eng RM, Seite S (2017). The Role of Cutaneous Microbiota Harmony in Maintaining a Functional Skin Barrier. J Drugs Dermatol 16: 12-8.

11. Zeeuwen PL, Boekhorst J, van den Bogaard EH, de Koning HD, van de Kerkhof PM, Saulnier DM, et al (2012). Microbiome dynamics of human epidermis following skin barrier disruption. Genome Biol 13:R101.

12. Weyrich LS, Dixit S, Farrer AG, Cooper AJ, Cooper AJ (2015). The skin microbiome: Associations between altered microbial communities and disease. Australas J Dermatol 56: 268-74.

13. De Paepe K, Houben E, Adam R, Rogiers V (2007). Effective protection of the nasolabial skin by using lotionimpregnated paper handkerchiefs during an acute viral cold. J Cosmet Sci 29: 219-238. Symposium abstract 013 p. 223.

14. INCQS/FioCruz (1992). Padronização dos Testes de Sensibilidade a Antimicrobianos - Método Anvisa/CLSI (M2A8, Vol. $23 \mathrm{n}^{\circ}$ ). Método para a avaliação da atividade inibitória de preparação nas formas líquida, cremosa e sólida, Manual de Saneantes, Método de difusão em placas de ágar.

15. Gradim AJ, Anjos M (2015). Guia de Microbiologia 1ed. Disponível em: https://abihpec.org.br/guiamicrobiologia/files/assets/basic-html/page75.html. Acesso em: 16 janeiro.

16. Rios JL, Recio MC, Villar A (1988). Screening methods for natural products with antimicrobial activity: a review of the literature. J Ethnopharmacol 23:127-149.

17. Brandwein M, Steinberg D, Meshner S (2016). Microbial biofilms and the human skin microbiome. NPJ Biofilms Microbiomes 2:3.

18. Eberlin S, Facchini G, Silva GH, Pinheiro ALTA, Pinheiro AS (2020). Metodologías para evaluar la eficacia de los productos en la regulación de la microbiota cutânea Arte y Ciencia Cosmética 32(77): 74- 81. ISSN 0122-8072.

19. Eberlin S, Facchini G, Silva GH, Eberlin S, Bragatto AR, Pinheiro ALTA, Pinheiro AS (2021). Ex vivo Human skin model: an alternative test system for skin irritation and corrosion assays. ATLA (no prello).

20. Eberlin S, Facchini G, Silva MS, Silva GH, Pinheiro ALTA, Costa A (2020). Ex vivo Human skin model as a tool for atopic dermatitis assessment. J Am Acad Dermatol, 83(6) Supplement 1, AB161.

21. Eberlin S, Silva MS, Facchini G, Silva GH, Pinheiro ALTA, Eberlin S, Pinheiro AS (2020). The ex Vivo skin model as an alternative tool for the efficacy and safety evaluation of topical products. ATLA 48(1):10-22.

22. Harding CR, Scott IR. (2002) Stratum corneum moisturizing factors. In: J Leyden, A Rawlings, eds. Skin Moisturization. New York: Marcel Dekker: pp. 61-80.

23. Kam E, Resing KA, Lim S, Dale BA (1993). Identification of rat epidermal profilaggrin phosphatase as a member of the protein phosphatase 2A family. J Cell Sci 106: 219-226.

24. Haugen-Scofield J, Resing KA, Dale BA (1988). Characterization of an epidermal phosphatase specific for filaggrin phosphorylated by casein kinase II. J Invest Dermatol 91:533-559.

25. Resing KA, Walsh KA, Dale BA (1984). Identification of two intermediates during processing of profilaggrin to filaggrin in 
neonatalmouse epidermis. J Cell Biol 99:1372-1378.

26. Resing KA, Walsh KA, Haugen-Scofield J, Dale BA (1989). Identification of proteolytic cleavage sites in the conversion of profilaggrin to filaggrin in mammalian epidermis. J Biol Chem 264: 1837-1845.

27. Harding CR, Scott IR (1983). Histidine-rich proteins (filaggrins). Structural and functional heterogeneity during epidermal differentiation. J Mol Biol 170: 651-673.

28. Yosipovitch G, Yarnitzky D (1997). Quantitative sensory testing. In: Dermatotoxicology Methods: The Laboratory Worker"es Vade Mecum; Maibach, H.I., Marzulli, F.N., Eds.; Taylor \& Francis: New York, pp. 120-135.

29. Pons-Guiraud A (2004). Sensitive skin: a complex and multifactorial syndrome. J. Cosm. Dermatol3, 145-148.

30. Costa A, Eberlin S, Polettini AJ, Pereira AFC, Pereira CS, Ferreira NMC, et al (2014). Neuromodulatory and AntiInflammatory Ingredient for Sensitive Skin: In Vitro Assessment. IADT 13:191-198.

31. Dreborg S (2001). Histamine reactivity of the skin. Allergy 56:359-364.

32. Columbo M, Horowitz EM, Kagey-Sobotka A, Lichtenstein LM (1996). Substance P activates the release of histamine from human skin mast cells through a pertussis toxin-sensitive and protein kinase c- dependent mechanism. Clin Immunol Immunopathol 81(1):68-73.

33. Douglas AD, Leeman SE (2011). Neurokinin-1 receptor: functional significance in the immune system in reference to selected infections and inflammation. Ann N Y Acad Sci 1217: 83-95.

34. Benedetto A, Yoshida T, Fridy S, Park JES, Kuo IH, Beck LA (2015). Histamine and skin barrier: are histamine antagonists useful for the prevention or treatment of atopic dermatitis? J Clin Med 4, 741- 755.

35. Kubo Y, Nakano K (1999). Regulation of histamine synthesis in mouse CD4+ and CD8+ T lymphocytes. Inflamm Res 48, 149-153.

36. Malaviya R, Morrison AR, Pentland AP (1996). Histamine in human epidermal cells is induced by ultraviolet light injury. $\mathrm{J}$ Inv Dermatol 106, 785-789.

37. Glatzer F, Gschwandtner M, Ehling S, Rossbach K, Janik K, Klos, et al (2013) Histamine induces proliferation in keratinocytes from patients with atopic dermatitis through the histamine 4 receptor. J Allergy Clin Immunol 132, 1358-1367.

38. Akdis CA, Simons FE (2006). Histamine receptors are hot in immunopharmacology. Eur J Pharmacol 533, 69-76.

39. Bielory L, Ghafoor S (2005). Histamine receptors and the conjunctiva. Curr Opin Allergy Clin Immunol 5, 437-440.

40. Gschwandtner M, Mildner M, Mlitz V, Gruber F, Eckhart L, Werfel, T, et al (2013). Histamine suppresses epidermal keratinocyte differentiation and impairs skin barrier function in a human skin model. Allergy 68, 37-47.

41. Keen MA, Hassan I (2016). Vitamin E in Dermatology. Indian Dermatol Online J 7(4): 311-315.

42. Nachbar F, Korting HC (1995). The role of vitamin-E in normal and damaged skin. J Mol Med 73, 7-17.

43. Jiang Q, Christen S, Shigenaga MK, Ames BN (2001). Gamma-tocopherol, the major form of vitamin E in the US diet, deserves more attention. Am J Clin Nutr 74:714-722.

44. Yoshida E, Watanabe T, Takata J, Yamazaki A, Karube Y, Kobayashi S (2006). Topical application of a novel, hydrophilic gamma-tocopherol derivative reduces photoinflammation in mice skin. J Invest Dermatol 126:1633-1640.

45. Beharka AA, Wu D, Serafini M, Meydani SN (2002). Mechanism of vitamin E inhibition ofcyclooxygenase activity in macrophages from old mice: Role of peroxynitrite. Free Radic Biol Med 32:503-511.

46. Tsoureli-Nikita E, Hercogova J, Lotti T, Menchini G (2002). Evaluation of dietary intake of vitamin $\mathrm{E}$ in the treatment of atopic dermatitis: A study of the clinical course and evaluation of the immunoglobulin E serum levels. Int J Dermato 41:146150.

47. Pallast EG, Schouten EG, de Waart FG, Fonk HC, Doekes G, von Blomberg BM, et al (1999). Effect of 50and 100-mg vitamin $\mathrm{E}$ supplements on cellular immune function in noninstitutionalized elderly persons. Am J Clin Nutr 69(6):1273-1281.

48. Reiter E, Jiang Q, Christen S (2007). Anti-inflammatory properties of $\alpha$ - and $\gamma$-tocopherol. Mol Aspects Med 28(5-6): 668-691.

49. Konger RL (2006). A new wrinkle on topical vitamin E and photo-inflammation: mechanistic studies of a hydrophilic $\gamma$ tocopherol derivative compared with $\alpha$-tocopherol. J Inv Dermatol 126, 1447-1449.

50. Feily A, Namazi MR (2009). Aloe vera in dermatology: a brief review. G Ital Dermatol Venereol 144(1):85-91.

51. Maenthai song $R$, Chaiyakunapruk $N$, Niruntraporn $S$, Kongkaew C (2007). The efficacy of aloe veraused for burn wound healing: A systematic review. Burns 33:713-718.

52. Hęś M, Dziedzic K, Górecka D, Jędrusek-Golińska A, Gujska E (2019). Aloe vera (L.) Webb. Natural Sources of Antioxidants - A Review. Plant Foods for Hum Nutr 74:255265.

53. Ray A, Aswatha SM (2013). An analysis of the influence of growth periods on physical appearance, and acemannan and elemental distribution of Aloe vera L.gel. Ind Crop Prod 48:3642.

54. Tanaka M, Yamamoto Y, Misawa E, Nabeshima K, Saito M, Yamauchi K, et al (2016). Effects of Aloe sterol supplementation on skin elasticity, hydration, and collagen score: a 12-week double-blind, randomized, controlled trial. Skin Pharmacol Physiol 29:309-317.

55. Hekmatpou D, Mehrabi F, Rahzani K, Aminiyan A (2019). The effect of aloe vera clinical trials on prevention and healing of skin wound: a systematic review. Iran J Med Sci 44(1):1-9.

56. Dal'Belo SE, Gaspar LR, Campos PMBGM (2006). Moisturizing effect of cosmetic formulations containing Aloe vera extract in different concentrations assessed by skin bioengineering techniques. Skin Res Technol 12(4):241-6.

57. Srivastava JK, Shankar E, Gupta S (2010). Chamomile: A herbal medicine of the past with bright future. Mol Med Report 3(6): 895-901.

58. Astin JA, Pelletier KR, Marie A, Haskell WL (2000). Complementary and alternative medicine use among elderly persons: one year analysis of blue shield medicare supplement. J Gerontol 5:M4-M9.

59. Sabale V, Kunjwani H, Sabale P (2011). Formulation and in vitro evaluation of the topical antiageingpreparation of the fruit of Benincasa hispida. J Ayurveda and Integr Med 2(3): 124128.

60. Jadoon S, Karim S, Asad MHHB, Akram MR, Kalsoom A, Khan AK, et al (2015). Anti-aging potential of phytoextract loaded-pharmaceutical creams for human skin cell longetivity. oxidative medicine and cellular longevity, Article ID 709628, 17 pages.

61. Mahmood T, Akhtar N, Khan BA, Khan HMS,Saeed T (2010). Outcomes of $3 \%$ green tea emulsion on skin sebum production in male volunteers. Bosnian J Bas Med Sci 10(3): 260-264.

62. Mahmood T, Akhtar N, Khan BA, Ahmad M, Khan HMS, 
Zaman SU (2010). Application of stable green tea extract cream on human cheeks. Int J Acad Res 2(2): 121-126.

63. Almeida IF, Maleckova J, Saffi R, Monteiro H, Góios F, Amaral MH et al (2013). Characterizationof an antioxidant surfactant-free topical formulation containing Castanea sativa leaf extract. Drug Dev Ind Pharm 41(1):148-155.

64. McDaniel DH (2009). Clinical safety and efficacy in photoaged skin with CoffeeBerry extract, a natural antioxidant. Cosm Dermatol 22(12): 610-616.

65. Ali A, Akhtar N, Chowdhary F (2014). Enhancement of human skin facial revitalization by moringa leaf extract cream. Postepy Dermatologii i Alergologii 3(2): 71-76.

66. Akhtar N, Hisham J, Khan HMS, Khan BA, Mahmood T, Saeed T (2012). Whitening and antierythemic effect of a cream containing Morus alba extract. Hygeia J Drugs and Med 4(1): 97-103, 2012.

67. Waqas MK, Akhtar N, Khan HMS, Mustafa R, Murtaza G (2014). Stability study of a cosmetic emulsion loaded with Tamarindus indica seeds extract. Latin Am J of Pharm 33(5): 731-738. 
Ready to submit your research? Choose Auctores and benefit from:

* fast, convenient online submission

* rigorous peer review by experienced research in your field

* rapid publication on acceptance

* authors retain copyrights

* unique DOI for all articles

* immediate, unrestricted online access

At Auctores, research is always in progress.

Learn more www.auctoresonline.org/journals/journal-of-clinicalresearch-and-reports- 